\title{
FORMATION OF A CYTOTOXIC METABOLITE FROM GENTAMICIN BY LIVER
}

\author{
May Y. Huang and Jochen Schacht* \\ Kresge Hearing Research Institute and Department of Otolaryngology, University of Michigan School of \\ Medicine, Ann Arbor, MI 48109-0506, U.S.A.
}

(Accepted 10 October 1990)

The aminoglycoside antibiotics have been a mainstay in the systemic therapy for serious Gram-negative infections for nearly five decades. The adverse effects of ototoxicity and nephrotoxicity, first recognized after the introduction of streptomycin in the 1940s [1,2], still pose many unresolved basic questions and continue to complicate the clinical application of these drugs. It has been well-documented that aminoglycoside-induced hearing loss is related to the progressive and irreversible destruction of cochlear outer hair cells from the inner ear [3]. A variety of biochemical effects have been described and mechanisms of toxicity advanced [4], but no cellular event has yet been causally linked to cytotoxicity or cell death.

In contrast to their well-documented toxicity in vivo, aminoglycosides have no acute toxicity to either cochlear or renal cells in vitro $[5,6]$. This discrepancy between in vivo and in vitro effects suggests that a metabolic event is required for the toxic actions of these antibiotics. The possibility of aminoglycoside-derived toxic metabolites has seldom been considered, and direct experimental evidence for such metabolites has been lacking $[7,8]$. Indeed, it has remained dogma that these drugs do not undergo significant metabolism prior to their renal elimination [9].

In this study, we used isolated cochlear outer hair cells in a recently developed cytotoxicity assay $[5,10]$ to test the toxicity of aminoglycosides after incubation with drug-metabolizing hepatic enzymes. The subcellular S9 fraction employed ( $9000 \mathrm{~g}$ supernatant from phenobarbital-treated animals) has been well-established for xenobiotic metabolism in the Ames test [11]. Gentamicin incubated with the hepatic enzymes decreased the viability of the cells, while the untreated parent antibiotic had no cytotoxic effect; evidence for the involvement of oxidative metabolism in the formation of the toxic metabolite is provided. These results should lead to new rational approaches to the mechanism and prevention of aminoglycoside-induced toxicity.

\section{METHODS}

Liver homogenates ( $3 \mathrm{~mL}$ of $0.15 \mathrm{M} \mathrm{KCl} / \mathrm{g}$ liver, dispersed with a Brinkmann Polytron for $10 \mathrm{sec}$ ) from guinea pigs treated with phenobarbital $(0.1 \%$ in drinking water for 10 days) were centrifuged at $9000 \mathrm{~g}$ for $10 \mathrm{~min}$ and the supernatants ( $\mathrm{S} 9$ ) stored at $-80^{\circ}$ in glass vials. The $\mathrm{S} 9$ fraction was combined for each experiment with $100 \mathrm{mM}$ sodium phosphate buffer (pH 7.40), $4 \mathrm{mM}$ NADP, $5 \mathrm{mM}$ glucose-6-phosphate, $30 \mathrm{mM} \mathrm{KCl}$ and $7 \mathrm{mM}$ $\mathrm{MgCl}_{2}$ [11], and $10 \mathrm{mM}$ gentamicin sulfate (Sigma, St. Louis, MO) was incubated with this "S9 Mix" at a protein concentration of $4 \pm 1 \mathrm{mg} / \mathrm{mL}$ for $60 \mathrm{~min}$ at $37^{\circ}$ in glass tubes. The incubation mixture was heat-treated $\left(55^{\circ}\right.$ for $1.5 \mathrm{~min})$ to remove protein without inactivating the metabolite, centrifuged $(10,000 \mathrm{~g}$ for $10 \mathrm{~min})$, and kept on ice.

Outer hair cells were isolated from the three upper cochlear turns of pigmented guinea pigs (200-300 g) by microdissection and brief treatment with collagenase $(0.5 \mathrm{mg} / \mathrm{mL}$ for $10 \mathrm{~min})$. They were maintained at room temperature in Hanks' Balanced Salt Solution without bicarbonate, buffered with $5 \mathrm{mM}$ HEPES, pH 7.40, and osmolarity adjusted with $\mathrm{NaCl}$ to $300 \mathrm{mOsM}$ [12]. To assay cytotoxicity, isolated hair cells were exposed at room temperature to a 1:10 dilution $(v / v)$ of the deproteinated incubation medium in droplets of Hanks' solution. Viability was quantitated based on the exclusion of the nuclear dye propidium iodide, added immediately prior to cell counting (final concentration, $4 \mu \mathrm{M}$ ). Stained or enucleated cells were counted as dead.

\footnotetext{
* To whom correspondence should be addressed.
} 


\section{RESULTS}

Metabolism of gentamicin. After incubation with the S9 Mix, metabolized gentamicin significantly decreased the viability of cochlear outer hair cells (Figure I and Table I). This was accompanied by morphologic evidence of cell destruction, such as swelling, vacuolization, granularity, loss of birefringence and occasional enucleation. In contrast, unmetabolized gentamicin was not cytotoxic under these conditions (Figure I), in agreement with our previous data [5].

Incubations of the S9 Mix without aminoglycoside antibiotic produced no apparent cytotoxic effect, demonstrating the absence of intrinsic toxic substances in the subcellular fraction (Table I). S9 fraction heatinactivated prior to incubation with gentamicin did not generate a toxic product, supporting an enzymatic basis for the formation of cytotoxic metabolite(s). Since commercial gentamicin is a mixture of the structurally related gentamicin $\mathrm{C}_{1}, \mathrm{C}_{1 \mathrm{a}}$ and $\mathrm{C}_{2}$ (composition and purity confirmed by TLC analysis [13]) it remains to be established whether all or which of the components give rise to a metabolite. Preliminary experiments suggest that metabolism also renders other aminoglycoside antibiotics, such as tobramycin and amikacin, cytotoxic.

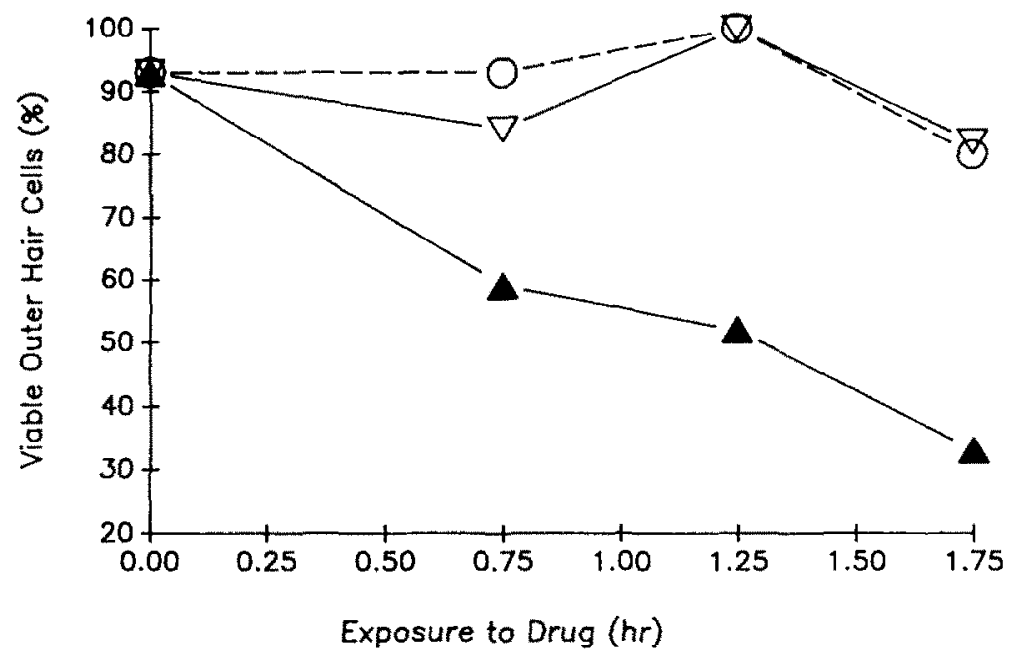

Figure I. Time course of cytotoxicity of metabolized gentamicin. The viability of isolated outer hair cells was assessed as described in Methods after exposure to: gentamicin-free Hanks' medium ( $O$ ), gentamicin incubated with $S 9$ Mix ( $\Delta$ ), or gentamicin in a reagent blank without the $S 9$ fraction $(\nabla)$. Each value is derived from observations of at least 100 cells.

Table I. Requirement for gentamicin and active $\$ 9$ fraction in the formation of cytotoxic metabolite

\begin{tabular}{lccc}
\hline Condition & $\begin{array}{c}\text { Cells } \\
\text { (number observed) }\end{array}$ & Experiments & $\begin{array}{c}\text { Viable cells } \\
(\% \text { of total) }\end{array}$ \\
\hline Ilanks' medium $^{\text {S9 Mix + gentamicin }}{ }^{a}$ & 660 & 20 & $90 \pm 6$ \\
S9 Mix alone $^{b}$ & 442 & 14 & $54 \pm 9$ \\
Heated S9 + gentamicin $^{c}$ & 218 & 6 & $91 \pm 7$ \\
\hline
\end{tabular}

The viability of isolated cochlear outer hair cells was determined as described in Methods after a 75-min exposure at room temperature to: (a) gentamicin incubated with S9 Mix; (b) S9 Mix incubated without gentamicin; (c) gentamicin incubated with a heat-inactivated $S 9$ fraction ( $100^{\circ}$ for $1.5 \mathrm{~min}$ ) in the Mix. For each condition, mean viability $\pm S D$ was determined from the number of independent experiments and total number of cells indicated. Statistical significance of differences: ' $S 9+$ gentamicin' differed significantly ( $\mathrm{P}<0.001$; twosample $t$-test) from each of the other conditions. ' $S 9$ alone' and 'heated $S 9+$ gentamicin' were not different from controls in Hanks' medium. 
Inhibition of gentamicin metabolism. Hepatic drug metabolism is frequently associated with cytochrome P450 or similar oxygenases. To assess the possible contribution of such enzymes, oxidative reactions were suppressed in the incubation (Table II). Two independent approaches were employed: NADP was omitted to prevent the generation of NADPH, and ketoconazole was added as a broad-spectrum inhibitor of oxidative xenobiotic metabolism $[14,15]$. Under both conditions, the formation of a toxic product was essentially prevented and outer hair cells remained viable. These results strongly suggest a role for mono-oxygenases in the metabolism of aminoglycosides.

Table II. Requirement for oxidative metabolism in the formation of cytotoxic metabolite

\begin{tabular}{lccc}
\hline Condition & $\begin{array}{c}\text { Cells } \\
\text { (number observed) }\end{array}$ & Experiments & $\begin{array}{c}\text { Viable cells } \\
\text { (\% of total) }\end{array}$ \\
\hline $\begin{array}{l}\text { Hanks' medium } \\
\text { S9 Mix + gentamicin }\end{array}$ & 253 & 5 & $88 \pm 8$ \\
$\begin{array}{l}\text { S9 Mix + gentamicin } \\
\text { but NADP omitted }\end{array}$ & 203 & 5 & $56 \pm 5$ \\
$\begin{array}{c}\text { S9 Mix + gentamicin } \\
\text { and ketoconazole added }\end{array}$ & 255 & 5 & $91 \pm 3$ \\
\hline
\end{tabular}

Oxidative metabolism was inhibited by omission of NADP from or addition of $250 \mu \mathrm{M}$ ketoconazole (in $0.5 \%$ aqueous ethanol, v/v) to the $\mathrm{S} 9 \mathrm{Mix}$ as noted in the table. The viability of isolated outer hair cells was assessed as described in Mcthods after a 75-min exposure at room temperaturc to each condition indicated. Mean viability \pm SD was determined from the number of independent experiments and total number of cells indicated. Statistical significance of differences: ' $S 9+$ gentamicin' was significantly different $(P<0.001$; two-sample $t$-test $)$ from each of the other conditions. 'NADP omitted' and 'ketoconazole added' were not different from control incubations in Hanks' medium.

\section{DISCUSSION}

Our data provide the first direct demonstration that metabolism is required for the cytotoxicity of aminoglycosides. While several pathways appear compatible with the data at this point, an enzymatic oxidation producing one or more cytotoxic metabolites from gentamicin appears the most likely reaction. Regardless of the mechanism, the novel and important aspect of these results is the fact that the cytotoxic species is not the parent aminoglycoside but a metabolite which is stable for at least several hours following mild heat treatment.

The existence of a toxic metabolic product may explain why it has been exceedingly difficult to formulate a molecular mechanism of aminoglycoside toxicity. For example, the appearance of nephrotoxicity and ototoxicity is delayed for days to weeks, despite early peak drug levels in both cochlear and renal tissues [16]. The requirement for a toxic metabolite could account for the poor correlation between aminoglycoside concentrations and the histopathologic damage to either target organ $[9,16-18]$, and the delay in onset of clinical toxicity could represent either the time necessary for induction of the metabolizing enzymes or for the metabolite to reach toxic levels.

The extent of metabolism of aminoglycosides in vivo is unknown. It is conceivable, however, that the concentration of the cytotoxic metabolite(s) is relatively low, having thus escaped traditional methods of detection. Only the development of outer hair cell isolation $[19,20]$ and the novel bioassay used here enabled direct measurement of cytotoxicity with adequately high sensitivity.

Further investigation will determine the intracellular location and the inducibility of the metabolizing enzyme(s), as well as the chemical structure of the potential metabolite(s). Considering the tissue specificity of aminoglycoside toxicity, it needs to be established to what extent this metabolism occurs in extra-hepatic tissues. A contribution by local metabolism to the development of organ-specific toxicity is suggested by reports that 
aminoglycosides applied directly into the fluids of the inner ear [21] or to otocyst organ cultures [22] produce toxic effects.

Past attempts to delineate mechanisms of aminoglycoside toxicity have met with limited success as have efforts to design preventative measures. Our findings should lead to new rational approaches to both the mechanism and prevention of aminoglycoside-induced toxicity.

Acknowledgements - This research was supported by NIH Grant DC-00124 and Training Grant DC-00024, and funds from the Department of Otolaryngology, The University of Michigan.

\section{REFERENCES}

1. Hinshaw HC and Feldman WH, Streptomycin in treatment of clinical tuberculosis: A preliminary report. Proc Mayo Clinic 20: 313-318, 1945.

2. Waksman SA, Streptomycin: Background, isolation, properties, and utilization. Science 118: 259-266, 1953.

3. Hawkins JE, Drug ototoxicity. In: Handbook of Sensory Physiology (Eds Keidel WD and Neff WD), pp. 707-748. Springer, New York, 1976.

4. Schacht J, Molecular mechanisms of drug-induced hearing loss. Hearing Res 22: 297-304, 1986.

5. Dulon D, Zajic G, Aran J-M and Schacht J, Aminoglycoside antibiotics impair calcium-entry but not viability and motility of cochlear outer hair cells. J Neurosci Res 24: 338-346, 1989.

6. Hori R, Yamamoto K, Saito H, Kohno $\mathrm{M}$ and Inui K, Effect of aminoglycoside antibiotics on cellular functions of kidney epithelial cell line (LLC-PK1): A model system for aminoglycoside nephrotoxocity. $J$ Pharmacol Exp Ther 230: 742-748, 1984.

7. Pierson MG and Møller AR, Prophylaxis of kanamycin-induced ototoxicity by a radioprotectant. Hearing Res 4: 79-87, 1981.

8. Hoffman DW, Whitworth CA, Jones-King KL and Rybak LP, Potentiation of ototoxicity by glutathione depletion. Ann Otol Rhinol Laryngol 97: 36-41, 1988.

9. Sande MA and Mandell GL, In: The Pharmacological Basis of Therapeutics (Eds Goodman AG, Gilman A, Rall TW and Murad F), 7th Edn, pp. 1150-1169. Macmillan, New York, 1985.

10. Huang $\mathrm{M}$, Dulon $\mathrm{D}$ and Schacht J, Outer hair cells as potential targets of inflammatory mediators. Ann Otol Rhinol Laryngol 99 (S148): 35-38, 1990.

11. Maron DM and Ames BN, In: Handbook of Mutagenicity Test Procedures (Eds Kilbey BJ, Legator M, Nichols W and Ramel C), pp. 93-140. Elsevier Science Publishers, Amsterdam, 1984.

12. Zajic $\mathrm{G}$ and Schacht $\mathrm{J}$, Comparison of isolated outer hair cells from five mammalian species. Hearing Res 26: 249-256, 1987.

13. Sekkat $\mathbf{M}$, Fabre H, Simeon De Buochberg $\mathbf{M}$ and Mandrou B, Determination of aminoglycosides in pharmaceutical formulations - I. Thin-layer chromatography. J Pharm Biomed Analysis 7: 883-892, 1989.

14. Sheets JJ and Mason JI, Ketoconazole: A potent inhibitor of cytochrome P-450-dependent drug metabolism in liver. Drug Metab Dispos 12: 603-606, 1984.

15. Meredith CG, Maldonado AL and Speeg KV, The effect of ketoconazole on hepatic drug metabolism in the rat in vivo and in vitro. Drug Metab Dispos 13: 156-162, 1985.

16. Tran Ba Huy $\mathrm{P}$, Bernard $\mathrm{P}$ and Schacht $\mathrm{J}$, Kinetics of gentamicin uptake and release in the rat: Comparison of inner ear tissues and fluids with other organs. J Clin Invest 77: 1492-1500, 1986.

17. Koren G, Klein J and MacLeod SM, The dissociation between aminoglycoside serum concentrations and nephrotoxicity. Life Sci 43: 1817-1823, 1988.

18. Huang MY and Schacht J, Drug-induced ototoxicity: Pathogenesis and prevention. Med Toxicol Adverse Drug Exp 4: 452-467, 1989.

19. Brownell WE, Bader CR, Bertrand D and de Ribeaupierre Y, Evoked mechanical responses of isolated cochlear hair cells. Science 227: 194-196, 1985.

20. Zenner HP, Zimmermann $U$ and Schmitt U, Reversible contraction of isolated mammalian cochlear hair cells. Hearing Res 18: 127-133, 1985.

21. Takada A and Schacht J, Calcium antagonism and reversibility of gentamicin-induced loss of cochlear microphonics in the guinea pig. Hearing Res 8: 179-186, 1982.

22. Anniko M, Takada A and Schacht J, Comparative ototoxicities of gentamicin and netilmicin in three model systems. Am J Otolaryngol 3: 422-433, 1982. 